\title{
Fluxo de Caixa Livre: Valuation de Uma Empresa do Setor Aéreo Brasileiro
}

\author{
Free Cash Flow: Valuation of a Company of the Brazilian Travel Industry
}

Neirilane Silva de Almeida
Mestranda em Administração na Faculdade de Gestão de Negócios da Universidade Federal de Uberlândia
Ronaldo Freitas da Silva
Kárem Cristina de Souza Ribeiro
Mestrando em Administração na Faculdade de
$\begin{array}{cc}\text { Gestão de Negócios da Universidade Federal de } \\ \text { Uberlândia } & \text { Ph.D em Administração (FEA/USP) } \\ & \text { Poutora em Administração (FEA/USP) }\end{array}$

\begin{abstract}
Resumo
O fluxo de caixa livre é considerado, por diversos autores, como uma das ferramentas mais efetivas para a mensuração do valor de uma empresa, por trazer o valor presente de expectativas futuras a uma taxa de desconto condizente com a realidade econômica em que a organização está inserida. Sendo assim, a proposta deste trabalho constitui em verificar qual o valor da empresa GOL através do Fluxo de Caixa Livre. Utilizou-se esta empresa, pois a mesma foi criada há nove anos e com a aquisição da Varig em 2007 divulga expectativas de expansão de mercado tanto nacional como internacionalmente. Como metodologia, realizouse uma pesquisa descritiva com abordagem quantitativa, através de um estudo de caso. Os resultados demonstraram que o valor da empresa, através do Fluxo de Caixa Livre é 10,74\% menor do que o valor patrimonial e que a diminuição do Fluxo de Caixa Livre no decorrer dos anos projetados é proveniente, principalmente, do crescimento percentual maior dos custos e das despesas gerais e administrativas, em relação ao crescimento da receita.
\end{abstract}

Palavras-chave: Valuation; Fluxo de Caixa Livre; GOL.

\section{Abstract}

The free cash flow is considered by many authors as one of the most effective tools for measuring the value of a company, because bring the present value the future expectations of a discounted rate commensurate with the economic reality in which the organization is inserted. Therefore, the purpose of this study is to determine which firm value through GOL's free cash flow. This paper used this company, because it was created nine years ago and with the acquisition of Varig in 2007 discloses expectations of market expansion both domestically and internationally. As a methodology, there was a descriptive research with quantitative approach, through a case study. The results showed that the value of the company, through the Free Cash Flow is 10.74\% lower than the net asset value and that the decrease in Free Cash Flow over the years designed comes mainly from growth higher percentage of costs and general and administrative expenses in relation to revenue growth.

Key-words: Valuation; Free Cash Flow; GOL.

\section{INTRODUÇÃO}

Existem vários modelos e métodos de avaliação de empresas que podem ser utilizados em conjunto ou separadamente, sendo que, em sua maioria, nenhum modelo fornece um valor preciso e único para uma empresa, mas sim uma estimativa por considerar premissas, hipóteses e tendências, muitas vezes, subjetivas (DAMODARAN, 2002). 
Assaf Neto (2003) confirma a existência de inúmeras metodologias de avaliação de empresas e ratifica a dificuldade de se calcular o valor justo, uma vez que a mensuração exige coerência e rigor na escolha do modelo de avaliação a ser adotado.

Neste sentido, o fluxo de caixa é tido como aquele que melhor revela a efetiva capacidade de geração de riqueza de um empreendimento, uma vez que traz o valor presente de benefícios futuros esperados a uma taxa de desconto apropriada e retrata a realidade do ambiente econômico no qual a empresa se encontra inserida (BRIGHAM et al 2001; MARTINS, 2001; ASSAF NETO, 2003).

A Gol Linhas Aéreas Inteligentes (GOL) adquiriu a Varig em 2007 com a intenção de aprimorar, no longo prazo, sua posição nos competitivos setores de transporte de passageiros brasileiro e latino-americano, expandindo tanto nacional quanto internacionalmente (GOL, 2010).

Sendo assim, considerando a importância da mensuração do valor das empresas, a premissa de que o fluxo de caixa é um dos instrumentos mais efetivos no cálculo do valor e o fato de que esta empresa possui expectativas de expansão, o problema que estimulou a realização deste estudo foi: qual é o valor da empresa GOL através do método do fluxo de caixa livre?

Diante disto, o presente artigo tem o objetivo de verificar o valor da empresa GOL Linhas Aéreas Inteligentes no ano de 2009, através do Fluxo de Caixa Livre, e averiguar se há discrepância com relação ao valor apresentado nas demonstrações financeiras da empresa. Para tanto, realizou-se um estudo descritivo com abordagem quantitativa, através de um estudo de caso da empresa GOL.

Este artigo apresenta seis seções. Após a introdução, a segunda seção aborda os modelos de avaliação de valor, em especial, o Fluxo de Caixa Livre, bem como o Custo Médio Ponderado de Capital e o valor da perpetuidade das organizações, enquanto a terceira seção aborda os procedimentos metodológicos. A quarta seção aborda uma análise do setor e da empresa e na quinta e sexta seções são apresentadas as análises e considerações finais sobre o assunto.

\section{FUNDAMENTAÇÃO TEÓRICA}

\subsection{Valuation}

A contabilidade, ciência que efetua os registros das transações das empresas e fornece informações aos seus usuários, possui limitações no que diz respeito à mensuração e à evidenciação do valor patrimonial, uma vez que a sua base tem respaldo no custo histórico e este reflete apenas o valor baseado em registros passados, fato que não demonstra a atual realidade de uma organização (ASSAF NETO, 2003).

Copelan et al (1990) defendem que é essencial que a empresa conheça o seu real valor, uma vez que este é considerado a melhor métrica de desempenho por ser um indicador que exige informações completas e de longo prazo.

Contudo, Perez e Famá (2003, p. 1), salientam que:

Se a avaliação de um único ativo ou investimento gera inúmeros questionamentos e até discordância quanto a metodologia adequada, o processo de avaliação de uma empresa, composta por inúmeros ativos, tangíveis e intangíveis, onde interagem interesses conflitantes, é mais complexo e delicado.

Neste sentido, na tentativa de calcular o valor justo de uma empresa, diversos autores apresentaram modelos de avaliação, não obstante, devido a sua complexidade e subjetividade 
a valorização de empresas ainda é tema de inúmeras discussões acadêmicas e profissionais (MARTINS, 2001; ASSAF NETO, 2003).

Segundo Müller e Teló (2003), dentre os modelos de avaliação destacam-se: o modelo baseado no Balanço Patrimonial, que visa encontrar o valor da empresa a partir da estimativa do valor de seus ativos; o modelo baseado na Demonstração do Resultado do Exercício (DRE), que busca encontrar o valor da empresa por meio do volume de lucros existentes, vendas e outros indicadores de resultado; o modelo baseado no Goodwill, que avalia o valor dos ativos da empresa e quantifica o potencial de geração de benefícios futuros; o modelo baseado no fluxo de caixa (cash flow), que busca determinar o valor da empresa pela estimativa do Fluxo de Caixa descontado a uma taxa de risco; e o modelo de criação de valor, que possibilita o conhecimento e mensuração do desempenho empresarial.

Dentre estes modelos, os métodos baseados no fluxo de caixa descontado, e em particular o método de desconto do fluxo de caixa livre, tem sido os mais recomendados pela literatura, uma vez que parte da premissa de que o valor da empresa deve ser obtido por meio de sua potencialidade em gerar caixas futuros (FERNANDEZ, 2001).

\subsection{Avaliação baseada em Fluxo de Caixa Livre}

Damodaran (2002, p. 214) afirma que "o valor de uma empresa é o valor presente de seus fluxos de caixa previstos ao longo de sua vida". No mesmo sentido, Assaf Neto (2003, p. 586) ratifica que:

Uma empresa é avaliada por sua riqueza econômica expressa a valor presente, dimensionada pelos benefícios de caixa esperados no futuro e descontados por uma taxa de atratividade que reflete o custo de oportunidade dos vários provedores de capital.

Brealey e Myers (2000, p. 28) defendem o procedimento de desconto das entradas e saídas esperadas de recursos financeiros ao valor presente ao mencionarem que:

Os fluxos de caixa são atualizados por duas simples razões: a primeira, porque um dólar disponível hoje vale mais que um dólar disponível amanhã, e, a segunda, porque um dólar com risco vale menos que um dólar sem risco. As fórmulas do VP (valor presente) e do VPL (valor presente líquido) são expressões numéricas que quantificam essas idéias. Damos atenção às taxas de remuneração prevalecentes nos mercados de capitais para determinar a influência do tempo e do risco sobre a taxa de atualização. Com o cálculo do valor presente de um ativo estamos, de fato, a estimar quanto as pessoas pagarão por ele, se tiverem como alternativa um investimento no mercado de capitais.

Para Brigham et al (2001, p. 62):

O fluxo livre de caixa representa o caixa que está efetivamente disponível para distribuição aos investidores. Portanto, a forma pela qual os gestores podem fazer com que suas empresas sejam mais valiosas é aumentar seus fluxos livres de caixa.

Brown (1996) ratifica e orienta que o fluxo de caixa livre não deve ser confundido com o fluxo de caixa tradicional, pois aquele é proveniente das operações correntes e está disponível para distribuição, sem afetar o nível de crescimento do empreendimento. Sendo 
assim, o termo livre pode ser associado ao excedente de caixa efetivamente disponível para a distribuição ou aumento de capital.

O fluxo de caixa livre (Quadro 1) é gerado pela empresa após a dedução dos impostos, investimentos permanentes e variações esperadas no capital circulante líquido (MARTINS, 2001).

\begin{tabular}{|l|}
\multicolumn{1}{|c|}{ Fluxo de Caixa Livre } \\
(=) Receita Líquida de Vendas e/ou Serviços \\
(-) Custo de Bens e/ou Serviços Vendidos \\
(-) Despesas Com Vendas \\
(-) Despesas Gerais e Administrativas \\
(=) Lucro antes de juros e impostos sobre o lucro (EBIT) \\
(+) Depreciação \\
(=) Lucros antes dos juros, tributos sobre o lucro, depreciação, \\
amortização e exaustão (EBITDA) \\
(-) Imposto de Renda/Contribuição Social \\
(=) Geração de Caixa Operacional \\
(-) Investimentos Permanentes \\
(-) Investimentos Circulantes \\
(=) Fluxo de Caixa Livre das Operações
\end{tabular}

Quadro 1: Modelo de Fluxo de Caixa Livre

Fonte: MARTINS (2001, p. 281)

O modelo mostra as deduções e adições que devem ser efetuadas à receita líquida de vendas e/ou serviços, sendo que o resultado é utilizado para mensurar o valor do empreendimento. Para tal mensuração, como os fluxos de caixa livre são descontados a valor presente, Gropelli e Nikbakth (2006) sugere a determinação do custo de cada fonte de financiamento de capital e a ponderação desses custos de acordo com a importância correspondente desses capitais como fonte de fundos, para a determinação da taxa de desconto e, conseqüentemente, do efetivo valor da empresa.

\section{3 Custo médio ponderado de capital}

O custo do capital de uma empresa é fator de fundamental importância para uma variedade de decisões a serem tomadas, conforme Easley e O'Hara (2004) salientam. Para Ross, Westerfield e Jaffe (1995, p. 358) "o custo de capital é uma média ponderada entre o custo de capital de terceiros e o custo de capital próprio". Isto fica evidente, nas palavras de Copeland et al (1990) ao explicarem que tanto credores quanto acionistas esperam ser remunerados pelo custo de oportunidade do investimento de seus recursos em uma determinada empresa, em vez de outra de risco semelhante.

No mesmo sentido, Assaf Neto (2003) expõe que o CMPC é uma média ponderada dos diversos tipos de capital que a empresa usa, tipicamente dívidas onerosas (curto prazo e longo prazo) e capital próprio. O autor ainda afirma que o custo total de capital representa a taxa de atratividade da empresa, indicando, por conseguinte, a remuneração mínima que deve ser exigida na alocação de capital, de forma a maximizar seu valor de mercado.

A metodologia de mensuração do CMPC pode ser calculada de acordo com ponderações baseadas em valores contábeis, em valores determinados pelo mercado ou, ainda, com base em uma estrutura de capital admitida como meta pela empresa. O importante, é que em uma avaliação, o CMPC seja coerente com todo o processo de avaliação desempenhado e 
em particular com a abordagem do método de fluxo de caixa livre (COPELAND et al, 1990; ASSAF NETO, 2003).

A apuração do CMPC, citado por Martins (2001), passa por três passos: o cálculo do custo de cada fonte financeira específica; a determinação da porcentagem de cada fonte financeira no total do financiamento; e a soma dos produtos do primeiro e do segundo item.

No que concerne ao custo de capital de terceiros, Assaf Neto (2003) salienta que este pode ser definido com base nos passivos onerosos, empréstimos e financiamentos, e pode ser obtido, após a apuração do Imposto de Renda de Pessoa Jurídica (IRPJ) e da Contribuição Social sobre o Lucro Líquido (CSLL) de acordo com a fórmula apresentada a seguir e representada no exemplo do (Quadro 2), onde estima-se que Ki é o custo de capital de terceiros e que as alíquotas de IRPJ e CSLL correspondem a 34\%, levando em consideração o percentual de $15 \%$ de IRPJ mais $10 \%$ de adicional e 9\% para a CSLL.

Já no que concerne ao custo do capital próprio, Martins e Assaf Neto (1986, p. 482) afirmam que:

\begin{abstract}
Ao levantar recursos no mercado acionário, ou mesmo ao reter parte de seus lucros, a empresa deverá aplicá-los em projetos (ativos) rentáveis, de modo que o retorno produzido possa remunerar seus acionistas em nível equivalente às suas expectativas. Dessa forma, a remuneração mínima exigida pelos acionistas constitui-se, em última análise, no custo de capital próprio da empresa.
\end{abstract}

$\mathrm{Na}$ literatura é possível observar diversas alternativas para a mensuração deste custo como o Capital Asset Pricing Model (CAPM); a Arbitrage Pricing Model (APM) e o Modelo de Gordon, entre outros, e devido a estas diversas hipóteses de cálculos este assunto é considerado um segmento complexo das finanças corporativas (MARTINS, 2001).

Após o cálculo do custo de capital próprio, pode-se calcular o CMPC conforme fórmula definida por Martins (2001):

$$
C M P C=\sum_{j=1}^{n} \mathrm{kj} \cdot \mathrm{xj}
$$

Onde:

$\mathrm{CMPC}=$ Custo médio ponderado de capital;

$\mathrm{Kj}$ = custo específico de cada fonte de capital calculado após os tributos que incidem sobre o lucro;

$\mathrm{Xj}=$ participação relativa de cada fonte de capital no financiamento total.

\title{
2.4 Período explícito e Perpetuidade
}

Copeland et al (1990) indicam que o valor da empresa é representado pelo valor presente do fluxo de caixa durante o período de projeção explícita, mais o valor presente do fluxo de caixa depois deste.

O primeiro período, segundo Assaf Neto (2003, p. 594), descreve:

Um período previsível dos resultados operacionais esperados, sendo verificado nos primeiros anos de investimento. Esse período é geralmente estimado com base no desempenho possível de se prever de mercado e da economia, e no potencial de participação da empresa.

Após o cálculo do período explícito, Copeland et al (1990) defendem que o uso de premissas simplificadoras sobre o desempenho da empresa durante esse período, como uma taxa de crescimento constante, por exemplo, permite que se estime o valor da perpetuidade através do uso de uma de diversas fórmulas disponíveis. 
Segundo Martins (2001), a perpetuidade pode ser um dos elementos mais relevantes para a avaliação da empresa e pode ser calculada através da seguinte fórmula:

$$
\text { Perpetuidade }=\frac{\mathrm{FCL}(\mathrm{t}) \times(1+\mathrm{g})}{\mathrm{CMPC}-\mathrm{g}}
$$

Em que:

FCL $(\mathrm{t})$ - fluxo de caixa livre do último período da projeção;

CMPC - custo médio ponderado de capital; e

$\mathrm{g}$ - taxa de crescimento

As abordagens mais usadas para estimar a taxa de crescimento (g), segundo Brigham et al (2001) são: as taxas de crescimento históricas; o período de tempo; a taxa de crescimento composta ponto a ponto; a taxa de crescimento composta média a média; a regressão dos mínimos quadrados; a comparação dos lucros versus dividendos; e o modelo de crescimento pela retenção.

\section{ASPECTOS METODOLÓGICOS}

Em termos metodológicos, a pesquisa é descritiva, considerada de acordo com Selltiz et al (1975) como aquela que apresenta precisamente as características de uma situação, um grupo ou um indivíduo específico.

Com base nos procedimentos técnicos utilizados, esta pesquisa é do tipo estudo de caso que, de acordo com Yin (2005), se constitui em uma investigação que aborda apenas um fenômeno contemporâneo dentro de seu contexto da vida real, em especial quando os limites entre o fenômeno e o contexto não são claramente definidos.

Quanto à forma de abordagem do problema, esta é uma pesquisa quantitativa. Segundo Beuren (2004, p. 92) "esta abordagem caracteriza-se pelo emprego de instrumentos estáticos, tanto na coleta quanto no tratamento dos dados."

Para o cálculo do CMPC, utilizou-se os dados históricos das demonstrações financeiras atualizados pelo Índice Geral de Preços do Mercado (IGP-M), bem como as informações adicionais fornecidas pela empresa em seus relatórios anuais e a média da rentabilidade do setor aéreo como custo de oportunidade mínimo para os investidores da empresa.

Para a projeção do crescimento da Receita líquida da empresa, houve o uso do crescimento do Produto Interno Bruto (PIB) divulgado pelo Ministério da Fazenda, e para a projeção dos custos e despesas utilizou-se a média do crescimento de cada um destes dados e

\begin{tabular}{|c|c|c|c|c|c|c|c|}
\hline Dados daempresaGa & 2004 & 2005 & 2006 & 2007 & 2008 & 2009 & $\begin{array}{l}\text { Médiado } \\
\text { período }\end{array}$ \\
\hline Crescimento da Recaita Líquida de Vendas e a/Senviços & - & $61,34 \%$ & $42,45 \%$ & $30,65 \%$ & $29,04 \%$ & $-6,50 \%$ & $26,16 \%$ \\
\hline Cresaimento AstodeBenselauSeniços Vendidos & - & $75,39 \%$ & $47,64 \%$ & $70,87 \%$ & $25,82 \%$ & $-15,21 \%$ & $34,08 \%$ \\
\hline Relação do cresc. do A sto emrelação a Receita (34,08\%/ & 16\%) & & & & & & $130,29 \%$ \\
\hline Projeção cresaimerto da Receita pera 2010(PIB) & & & & & & & $5,20 \%$ \\
\hline Projeção Crescimento do Asto pera 2010 (5,20\% x 130,2 & & & & & & & $6,78 \%$ \\
\hline
\end{tabular}
a relação deles com o crescimento da receita, conforme explicitado no Quadro 3:

Quadro 3: Exemplo de cálculo das projeções

Fonte: Elaboração própria a partir de dados das Demonstrações Financeiras e das Projeções do PIB 
Para o desenvolvimento do estudo, determinou-se a utilização dos dados da empresa GOL, pelo fato de que esta foi criada há nove anos e, com a aquisição da Varig em 2007, divulga expectativas de expansão de mercado tanto nacional como internacionalmente.

\section{ANÁLISE DO SETOR E DA EMPRESA}

A GOL Linhas Aéreas iniciou suas atividades em 2001 com a proposta de entrar nos mercados que eram precariamente servidos ou não possuíam uma alternativa com tarifas menores e oferecer serviço simples e acessível. Neste contexto, ela foi a primeira companhia a introduzir com êxito práticas e tecnologias do segmento de transportes de baixo custo na América Latina com a estratégia de aumentar o tamanho de seu mercado atraindo novos passageiros ao facilitando a compra de suas passagens por clientes das classes de menor renda (GOL, 2010).

Em abril de 2007, a empresa adquiriu a VRG, companhia formada com ativos do antigo grupo Varig, com a intenção de aprimorar, no longo prazo, a sua posição nos competitivos setores de transporte de passageiros brasileiro e latino-americano. A aquisição está auxiliando no fornecimento de um serviço de transporte aéreo mais eficiente por meio de uma rede integrada em destinos no Brasil e na América do Sul (GOL, 2010).

Em 2009 a empresa conseguiu ampliar sua atuação no mercado e ofereceu cerca de 800 voos diários para 49 destinos que conectam todas as mais importantes cidades do Brasil e os nove principais mercados internacionais: Argentina, Bolívia, Chile, Colômbia, Paraguai, Peru, Uruguai e Venezuela (GOL, 2010).

No que diz respeito à rentabilidade do setor aéreo, ao observar o lucro das duas empresas de capital aberto (Gráfico 1) que negociam suas ações no sítio da Bovespa, pode-se observar que a GOL apresentou um crescimento em seu Resultado líquido em 2005, enquanto a TAM, sofreu uma queda em sua rentabilidade. Após a recuperação em 2006, as duas empresas diminuíram seu lucro no ano seguinte, contudo a GOL diminuiu de forma mais significativa do que a TAM. Em 2008, as duas companhias aéreas sofreram prejuízos consideráveis, com uma reversão, principalmente mais notória da companhia TAM no ano de 2009.

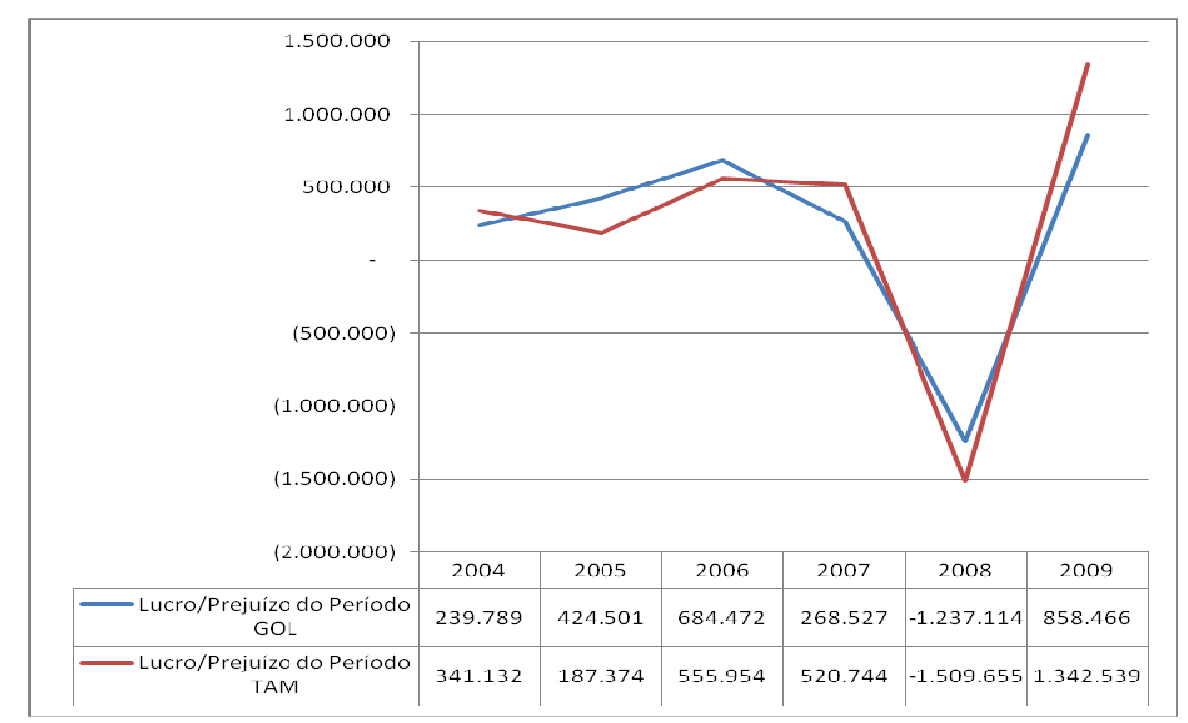

Gráfico 1: Variação do Lucro/ Prejuízo das empresas do setor aéreo

Fonte: Elaboração própria a partir de dados das Demonstrações Financeiras disponibilizadas pela GOL/TAM

O resultado da GOL, bem como a composição do ativo e passivo no período analisado podem ser observados na DRE e no Balanço Patrimonial da empresa disponibilizados no Quadro 4 e 5, respectivamente. 


\begin{tabular}{|c|c|c|c|c|c|c|}
\hline Denuntraçãocb|RealtacbcbEerádo & 2004 & 2006 & 2006 & 2007 & 2008 & 2000 \\
\hline 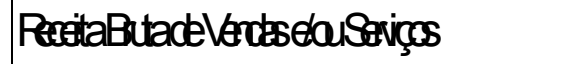 & $178 B 92$ & $278 C 84$ & 395188 & 518866 & 6671966 & 6252 \\
\hline 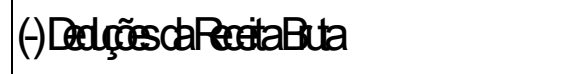 & $(7458)$ & $(\operatorname{tgc9} 9)$ & (19811) & (9164) & $(20230)$ & 12 \\
\hline (A) RecitalíqichceVendsedarSoriços & 165435 & 2009000 & 3802017 & 498722 & 640958 & 599206 \\
\hline 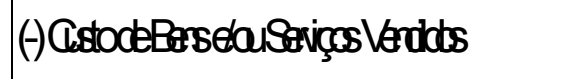 & (95221) & $(174556)$ & $(257.111)$ & $(44 B A B B)$ & $(550265)$ & $(4697.62)$ \\
\hline AResaltacbito & 69134 & 98355 & 124966 & 55384 & $993 B$ & 25073 \\
\hline 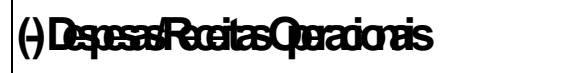 & $(298319$ & (4640) & $(4 \sqrt{159})$ & (577.89) & (200097) & 5162 \\
\hline (-)Converces & $(233143)$ & (3ळ/2) & $(4459)$ & (37.860) & (59873) & $(47479)$ \\
\hline (-) CraseAstimistatives & (48114) & (77.311) & $(20130)$ & $(26182)$ & $(3584)$ & $(42324)$ \\
\hline () Frraceries & (18059) & $(3334)$ & 12811 & 16198 & $(1106394)$ & 328\# \\
\hline (-) QresRerctasQmacionis & - & - & - & - & - & 268 \\
\hline$(t /)$ Realtabquaciond & 39818 & 47.:D & 75173 & 45974 & (1916) & 73480 \\
\hline 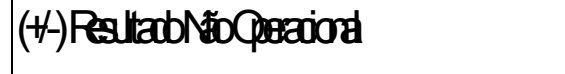 & - & - & BOT1 & (34374) & - & - \\
\hline 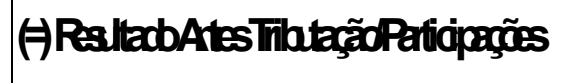 & 39818 & 47.:D & 8984 & 1160 & (1916) & $\mathbf{7 3 4 5 9}$ \\
\hline ()PoisãopzalReCotribiçãoseid & (13260) & (18250) & (उ.RB) & $(15291)$ & $(5.38)$ & $(69)$ \\
\hline$(t /) \mid \mathbb{R}$ [raicb & २651 & 2387 & (31.533) & 32198 & $11 \% 2$ & 15360 \\
\hline 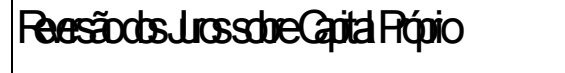 & - & 1360 & $13 \% 7$ & - & - & - \\
\hline AluodPgírocbPeíab & 23978 & 44501 & GA4R & æ27 & (1237.11) & 8BA6 \\
\hline
\end{tabular}

Quadro 4: Histórico da Demonstração de Resultado do Exercício da GOL

Fonte: Elaboração própria a partir de dados das demonstrações Financeiras disponibilizadas pela GOL 


\begin{tabular}{|c|c|c|c|c|c|c|}
\hline Balanço Patrimonial & 2004 & 2005 & 2006 & 2007 & 2008 & 2009 \\
\hline Ativo Qrculante & 1.312050 & 1.546707 & 2724.581 & 3067.927 & 1.65241 & 2406109 \\
\hline Disporibilidades & 849.091 & 869.035 & 1.706 .346 & 1.432801 & 591.611 & 1.441 .672 \\
\hline Céedtos & 402864 & 583.980 & 73275 & 981.380 & 456.694 & 605.433 \\
\hline Estoques & 21.038 & 40.683 & 75.165 & 215.777 & 194.015 & 143.810 \\
\hline atros & 39.057 & 53.009 & 210.313 & 437.969 & 411.151 & 215.194 \\
\hline Ativo Náo Qraulante & 217.433 & 709.149 & 1.055 .587 & 2696901 & 5082183 & 5994801 \\
\hline Ativo Realizável a Longo Prazo & 84.815 & 127.292 & 209.846 & 536169 & 1.046 .788 & 1.62333 \\
\hline Céédtos Diversos & N.108 & y1. $13 y$ & 64.253 & 530.568 & 1.U32819 & 1.6U6.kEs \\
\hline atros & 14.707 & 35.553 & 145.593 & 5.601 & 13.969 & 17.304 \\
\hline Ativo Pemmanente & 132618 & 581.857 & 845.741 & 2160.732 & 4035.395 & 4371.468 \\
\hline Investimentos & 1.260 & 1.829 & 2281 & 884.847 & - & \\
\hline Imdailizadb & 131.358 & 580.028 & 795.430 & 1.251 .423 & 3.011 .105 & 3.325 .713 \\
\hline Intangived & - & - & - & - & 1.024.290 & 1.045 .756 \\
\hline Dffericb & - & - & 48.030 & 24.462 & - & \\
\hline Ativo Total & 1.529 .483 & 2255856 & 3.780 .168 & 5764828 & 6734.654 & 8400.910 \\
\hline Passivo Oralante & 517.814 & 653.526 & 955.515 & 2192524 & 2502684 & 2359.099 \\
\hline Empréstimos eFinanciamentos & 118.349 & 54.016 & 140.688 & 824.132 & 809.504 & 455.016 \\
\hline Fomecedares & 36.436 & 73.924 & 124.110 & 326.364 & 283.719 & 362382 \\
\hline Impostos, Taxas e Contribuições & 51.515 & 83.750 & 139.394 & 152332 & 136.815 & 133.608 \\
\hline Dividendbs a Pagar & 60.676 & 101.482 & 42961 & 75.610 & 577 & 186.416 \\
\hline Proisões & - & - & - & 94.230 & 183.686 & 78.641 \\
\hline atros & 250.838 & 340.354 & 508.362 & 719.856 & 1.088 .383 & 1.143 .036 \\
\hline Passivo NÉo Gralante & 23.526 & 29.415 & 756.694 & 1.161.312 & 2897.57 & 3.201 .400 \\
\hline Empréstimos eFinanciamentos & - & - & 726.981 & 1.066 .102 & 1.023.224 & 747.383 \\
\hline Debêntures & - & - & - & - & - & 374.045 \\
\hline atros & 23.526 & 29.415 & 29.713 & 95.210 & 1.874 .353 & 2079.978 \\
\hline Patrimônio Ĺquidb & 988.143 & 1.572915 & 2067.959 & 2410.992 & 1.334 .393 & 2840.405 \\
\hline Capital Social Realizado & 719.474 & 991.204 & 993.654 & 1.363946 & 1.363 .946 & 2194794 \\
\hline Resenvas de Capital & 89.556 & 89.556 & 89.566 & 89.556 & 6820 & 48166 \\
\hline Ágona Conferência de Apoọes & & & & 60.369 & 60.369 & 31.076 \\
\hline ResenaEspecial deÁgiona Contrdada & & & & 29.187 & 29.187 & 29.181 \\
\hline Ações emTesauraia & & & & - & (41.180) & (11.887) \\
\hline Remuneração Dfferida- Opção de Açães & & & & - & 14.444 & 18.984 \\
\hline Astode Emissão de Açães & & & & - & - & (19.194) \\
\hline Reservas de Luaro & 179.113 & 492155 & 984.749 & 954823 & 918565 & $596 \curvearrowleft$ \\
\hline Retençãode Lưros & 179.113 & 485.744 & 989.071 & 954.823 & 918.565 & 596.627 \\
\hline Otras Resenes de Luaro & - & 6.411 & $(4.322)$ & - & - & - \\
\hline Ajustes de Avaliação Patrimonial & - & - & - & 2667 & (16.373) & 818 \\
\hline Lưro\&PrejúzosAcumulados & - & - & - & - & $(994565)$ & - \\
\hline Passivo Total & 1.529 .483 & 2255856 & 3.780 .168 & 5764828 & 6734.654 & 8400.910 \\
\hline
\end{tabular}

Quadro 5: Histórico do Balanço Patrimonial da Gol Linhas Aéreas

Fonte: Elaboração própria a partir de dados das demonstrações Financeiras disponibilizadas pela GOL

Através dos dados históricos apresentados no Balanço Patrimonial e na DRE, chega-se ao Fluxo de Caixa livre (Quadro 6) da empresa no período de 2009 a 2004. 


\begin{tabular}{|c|c|c|c|c|c|c|}
\hline Fluxo de Caixa Livre & 2004 & 2005 & 2006 & 2007 & 2008 & 2009 \\
\hline (=) Receita Líquida de Vendas e/ou Serviços & 1.654 .355 & 2.669 .090 & 3.802.017 & 4.967.262 & 6.409 .578 & 5.992 .685 \\
\hline (-) Custo de Bens e/ou Serviços Vendidos & (995.221) & $(1.745 .565)$ & $(2.577 .111)$ & (4.403.438) & (5.540.265) & $(4.697 .612)$ \\
\hline (-) Despesas Com Vendas & $(233.143)$ & $(335.722)$ & $(414.597)$ & $(367.866)$ & (588.735) & (474.792) \\
\hline (-) Despesas Gerais e Administrativas & $(48.114)$ & (77.341) & $(201.367)$ & $(256.182)$ & $(365.842)$ & $(452.324)$ \\
\hline (+) Outras Receitas Operacionais & - & - & - & - & - & 12.638 \\
\hline (=) Lucro antes de juros e impostos sobre o lucro (EBI7 & 377.877 & 510.462 & 608.942 & $(60.224)$ & (85.264) & 380.595 \\
\hline (+) Depreciação & 22.901 & 36.206 & 58.252 & 101.741 & 104.900 & 142.853 \\
\hline $\begin{array}{l}\text { (=) Lucros antes dos juros, tributos sobre o lucro, } \\
\text { depreciação, amortização e exaustão (EBITDA) }\end{array}$ & 400.778 & 546.668 & 667.194 & 41.517 & 19.636 & 523.448 \\
\hline (-) Imposto de Renda/Contribuição Social & $(132.680)$ & $(189.576)$ & $(257.706)$ & $(105.291)$ & $(57.338)$ & (609) \\
\hline (=) Geração de Caixa Operacional & 268.098 & 357.092 & 409.488 & (63.774) & (37.702) & 522.839 \\
\hline (-) Investimentos Permanentes e Circulantes & $(154.864)$ & $(484.129)$ & $(273.654)$ & $(245.941)$ & $(275.890)$ & (19.195) \\
\hline (=) Fluxo de Caixa Livre das Operações & 113.234 & (127.037) & 135.834 & (309.715) & (313.592) & 503.644 \\
\hline
\end{tabular}

Quadro 6: Histórico da Demonstração de Fluxo de Caixa Livre da GOL

Fonte: Elaboração própria a partir de dados das demonstrações Financeiras disponibilizadas pela GOL

Percebe-se que a empresa começou com o Fluxo de Caixa Livre positivo e teve resultados negativos no ano de 2005, 2007 e 2008, com a recuperação em 2009, sendo que este último ano apresentou o valor de fluxo de caixa livre mais significativo do período.

\section{ANÁLISE DOS RESULTADOS}

Para a projeção do Fluxo de Caixa nos cinco anos subseqüentes foram utilizados os percentuais apresentados no Quadro 7, que foram obtidos através da análise da variação de cada um destes dados no período de 2004 a 2009.

\begin{tabular}{|c|c|c|c|c|c|}
\hline Dados Históricos para projeção & 2010 & 2011 & 2012 & 2013 & 2014 \\
\hline Orescimento da ReceitaLíquida de Vendas e au/Senviços & $5,20 \%$ & $5,50 \%$ & $5,50 \%$ & $5,50 \%$ & $5,50 \%$ \\
\hline Orescimento Ousto de Bens elau Senviços Vendidos & $6,78 \%$ & $7,17 \%$ & $7,17 \%$ & $7,17 \%$ & $7,17 \%$ \\
\hline Orescimento Despesas Com Vendas & $3,21 \%$ & $3,40 \%$ & $3,40 \%$ & $3,40 \%$ & $3,40 \%$ \\
\hline Orescimento Despesas Gerais eAdministrativas & $10,43 \%$ & $11,03 \%$ & $11,03 \%$ & $11,03 \%$ & $11,03 \%$ \\
\hline Orescimento Depreciação & $7,72 \%$ & $8,16 \%$ & $8,16 \%$ & $8,16 \%$ & 8,16 \\
\hline Orescimento Imposto de $\mathrm{Re}$ & $4,13 \%$ & $4,37 \%$ & $4,37 \%$ & $4,37 \%$ & 4,37 \\
\hline Orescimento Investimentos Permanentes e Grculantes & $2,59 \%$ & $274 \%$ & $274 \%$ & $274 \%$ & 2,74 \\
\hline
\end{tabular}

Quadro 7: Informações projetadas através das demonstrações da empresa

Fonte: Elaboração própria a partir de dados das Demonstrações Financeiras e das Projeções do PIB

Para o cálculo da perpetuidade considerou-se como a Taxa de Crescimento $(\mathrm{g})$ a taxa do PIB disponibilizada pelo Ministério da Fazenda. Ao analisar o Fluxo de Caixa Livre dos períodos projetados da empresa (Quadro 8), percebe-se que tanto o custo de bens e ou/ serviços vendidos, como as despesas gerais e administrativas crescem, percentualmente, mais do que as receitas e que o valor do Fluxo de Caixa Livre, por sua vez, diminui com o passar dos anos. Isto ocorre, pois como o cálculo levou em consideração os dados históricos da empresa, principalmente no período de 2005 a 2007, a empresa teve um aumento percentual de custo maior do que o aumento da receita, e as despesas gerais e administrativas, com exceção dos anos de 2005 e 2007, cresceram mais, percentualmente, do que a receita. A depreciação, como não possui vínculo direto com a receita, cresceu mais no período do que esta e, portanto, a exemplo dos custos e das despesas gerais e administrativas, tem em sua projeção um percentual maior do que o projetado para a receita. 


\begin{tabular}{|c|c|c|c|c|c|}
\hline Fluxo de Caixa Livre & 2010 & 2011 & 2012 & 2013 & 2014 \\
\hline (=) Receita Líquida de Vendas e/ou Serviços & 6.304 .305 & 6.651 .041 & 7.016.849 & 7.402 .775 & 7.809 .928 \\
\hline (-) Custo de Bens elou Senviços Vendidos & $(5.015 .877)$ & $(5.375 .310)$ & $(5.760 .500)$ & (6.173.292) & $(6.615 .664)$ \\
\hline (-) Despesas Com Vendas & (490.035) & $(506.675)$ & $(523.880)$ & (541.669) & (560.062) \\
\hline (-) Despesas Gerais e Administrativas & (499.493) & $(554.585)$ & $(615.754)$ & (683.669) & (759.076) \\
\hline (=) Lucro antes de juros e impostos sobre o lucro (EBIT) & 298.900 & 214.472 & 116.715 & 4.145 & (124.874) \\
\hline (+) Depreciação & 153.876 & 166.436 & 180.020 & 194.713 & 210.605 \\
\hline $\begin{array}{l}\text { (=) Lucros antes dos Juros, tributos sobre o lucro, } \\
\text { depreciação, amortização e exaustão (EBITDA) }\end{array}$ & & 380.907 & & & 85.731 \\
\hline (-) Imposto de Renda/Contribuição Social & (634) & (662) & (691) & (721) & (753) \\
\hline (=) Geração de Caixa Operacional & 452142 & 380.245 & 296.044 & 198.137 & 84.978 \\
\hline (-) Investimentos Permanentes e Circulantes & (19.692) & (20.231) & $(20.785)$ & (21.354) & (21.939) \\
\hline (=) Fluxo de Caixa Livre das Operações & 432450 & 360.014 & 275.259 & 176.783 & 63.039 \\
\hline CMPC $=10 \%$ ao ano & 393.136 & 297.532 & 206.806 & 120.745 & 39.142 \\
\hline Valor Presente do Fuxo de Caixa Livre R\$ & $1.057 .362,16$ & & & & \\
\hline Taxa de Crescimento Anual & $5,50 \%$ & & & & \\
\hline Taxa de Desconto Anual & $10 \%$ & & & & \\
\hline Valor do Fuxo de Caixa Livre do Periodo n & 63.039 & & & & \\
\hline Perpetuidade & 1.477 .923 & & & & \\
\hline Valor Total da Empresa & 2.535 .285 & & & & \\
\hline
\end{tabular}

Quadro 8: Cálculo do valor da empresa através do Fluxo de Caixa Livre

Fonte: Elaboração própria a partir de dados históricos das Demonstrações Financeiras e Projeções do PIB

Verifica-se que o cálculo do valor total da empresa, através do Fluxo de Caixa Livre, é $\mathrm{R} \$$ 2.535.285 sendo que $\mathrm{R} \$ 1.057 .362,16$ é proveniente do período explícito, isto é, do período de cinco anos projetados e $\mathrm{R} \$ 1.477 .923$ é o valor da perpetuidade da empresa, respeitando as premissas estabelecidas pelo cálculo. O Gráfico 2, apresenta a comparação do valor encontrado no cálculo com o valor apresentado no Patrimônio Líquido da empresa em 2009.

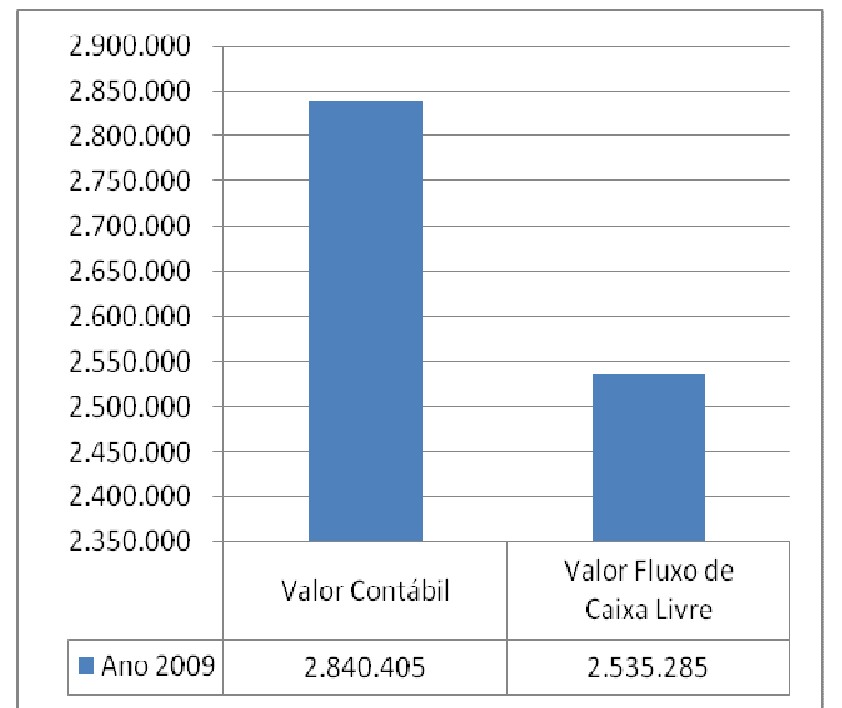

Gráfico 1: Comparação entre o Valor Contábil e o Valor Econômico

Fonte: Elaboração própria a partir de dados históricos das Demonstrações Financeiras 
Percebe-se que o valor através do Fluxo de Caixa Livre é menor do que o valor apresentado nos relatórios contábeis, o que demonstra que ao levar em consideração o valor presente das expectativas futuras da empresa e os demonstrativos, baseados em registros históricos, a empresa possui o valor $10,74 \%$ menor do que o valor contábil.

\section{CONSIDERAÇÕES FINAIS}

Deve-se salientar que para estabelecer as premissas para projeções é necessário utilizar registros históricos da empresa, bem como dados macroeconômicos, e obter a confirmação da gestão da empresa, contudo, devido a esta impossibilidade o presente estudo baseou-se em dados históricos e informações disponibilizadas pela empresa em seu site, bem como a taxa de crescimento do PIB fornecida pelo Ministério da Fazenda.

Através destes dados, chegou-se a uma taxa de custo médio ponderado de capital de dez por cento, e com ela houve a determinação do valor presente do fluxo de caixa livre e da perpetuidade da empresa.

Após as análises, verificou-se que valor total da empresa através do Fluxo de Caixa Livre, $R \$ 2.535 .285$, é $10,74 \%$ menor do que o valor patrimonial da empresa, $\mathrm{R} \$ 2.840 .405$ e que o aumento maior do percentual dos custos e das despesas gerais e administrativas do que o aumento das receitas foram os principais responsáveis pela diminuição do fluxo de caixa livre da empresa no período projetado.

Conforme defendido por diversos autores e elucidado neste estudo, o método de avaliação de empresas baseadas no fluxo de caixa livre é uma das ferramentas mais efetivas para a mensuração de valor da empresa, contudo, devido à subjetividade, o critério de cada avaliador, a ocorrência de fatores externos e a mudança do estágio da empresa, podem ocorrer variações inesperadas no crescimento, por exemplo, que não comprovarão a análise do valor efetuada na avaliação.

Esta pesquisa possui limitações no que diz respeito a não considerar o risco como uma das variáveis no cálculo do custo do capital próprio. Sendo assim, sugere-se que as próximas pesquisas considerem as condições de risco e verifiquem as discrepâncias com o valor contábil.

\section{REFERÊNCIAS}

ASSAF NETO, A. Finanças Corporativas e Valor. São Paulo: Atlas, 2003.

BEUREN, I. M. Como elaborar trabalhos monográficos em Contabilidade: teoria e pratica. São Paulo: Atlas, 2004.

BRIGHAM, E. F.; GAPENSKI, L.C.; EHRHARDT, M.C. Administração Financeira: Teoria e Prática. São Paulo: Atlas, 2001.

BREALEY, R. A.; MYERS, S. C. Principles of corporate finance. New York: McGrawHill, 2000.

BROWN, G. "Free Cash Flow" Appraisal... A better way?. The Appraisal Journal, n. 2, p. 171-182, April, 1996. Disponível em: http://www.accessmylibrary.com/article-1G118367691/free-cash-flow-appraisal.html. Acesso em: 01 de abr. de 2010.

COPELAND, T.; KOLLER, T.; MURRIN, J. Valuation: Measuring and managing the value of companies. New York: John Wiley \& Sons, Inc., 1990.

DAMODARAN, A. A face oculta da avaliação. São Paulo: Makron Books, 2002. 
EASLEY, D.; O'HARA, M. Information and the cost of capital. The Journal of Finance, vol. 59, n. 4. p. 1553-1583, 2004. Disponível em http://www.afajof.org/journal/abstract.asp/. Acesso em: 04 de abr. de 2010.

FERNANDEZ, P. Company valuation methods. The most common errors in valuations. Social Science Research Network, 2001. Disponível em: http://papers.ssrn.com/sol3/papers.cfm?abstract id=274973. Acesso em 02 de abr. de 2010.

GOL. Gol Linhas Aéreas Inteligentes. Disponível em http://www.voegol.com.br. Acesso em: 01 de abr. de 2010.

GROPELLI, A.A. NIKBAKTH, E. Administração Financeira. São Paulo: Saraiva, 2006.

MARTINS, E.; ASSAF NETO, A. Administração Financeira: as finanças das empresas sob condições inflacionárias. São Paulo: Atlas, 1986.

MARTINS, E. (Org). Avaliação de empresas: da mensuração contábil à econômica. FIPECAFI - Fundação Instituto de Pesquisas Contábeis, Atuariais e Financeiras. São Paulo: Atlas, 2001.

MÜlleR, A. N.; TELÓ, A. R. Modelos de avaliação de empresas. In: Revista FAE, Curitiba, v. 6, n. 2, p. 97-112, maio/dez. 2003.

MINISTÉRIO DA FAZENDA. Disponível em: <http:// www.fazenda.gov.br. Acesso em: 04 de abr. de 2010.

PEREZ, M. M.; FAMÁ, R. Métodos de Avaliação de Empresas e a Avaliação Judicial de Sociedades: uma Análise Crítica. In: VI SEMINÁRIOS EM ADMINISTRAÇÃO (SEMEAD) FEA-USP, São Paulo. São Paulo, 2003. Disponível em: <http://www.ead.fea.usp.br/ semead $>$ Acesso em 03 Abr. 2010.

ROSS, S.; WESTERFIELD, R.; JAFFE, J. Administração financeira. São Paulo: Atlas, 1995.

SElltiZ, C.; WrightSMAN, L.; COOK, S.; KIDDER, L. Métodos de Pesquisa nas Relações Sociais. 6 ${ }^{\mathrm{a}}$. Reimpressão EPU. São Paulo: Editora USP, 1975.

YIN, R. K. Estudo de Caso: Planejamento e Método. Porto Alegre: Bookman, 2005. 